\title{
The Mountain Research Initiative and Past Global Changes
}

Mel Reasoner 1 , Alfred Becker ${ }^{2}$, Harald Bugmann 3 , Lisa Graumlich ${ }^{4}$, Wilfried Haeberli 5 Bruno Messerli 6 and Frank 0ldfield 7

1 MRI Coordination Office, Bärenplatz 2 CH-3011 Bern, Switzerland, reasoner@sanw.unibe.ch

2 Potsdam Institute for Climate Impact Research, 14412 Potsdam, Germany, becker@pik-potsdam.de

3 Gebirgswaldökologie, ETH-Zentrum, 8092 Zürich, Switzerland, bugmann@fowi.ethz.ch

4 Mountain Research Center, Montana State University, Bozeman, MT 59717-3490 USA, lisa@montana.edu

5 Geographisches Institut, Universität Zürich, Zollikerstr. 107, 8008 Zürich, Switzerland, haeberli@geo.unizh.ch

6 Geographisches Institut, Hallerstrasse 12, University of Bern, CH-3012 Bern, Switzerland, messerli@giub.unibe.ch

7 PAGES, West Kirby, Wirral CH 48 2HF, UK, f.oldfield@btinternet.com

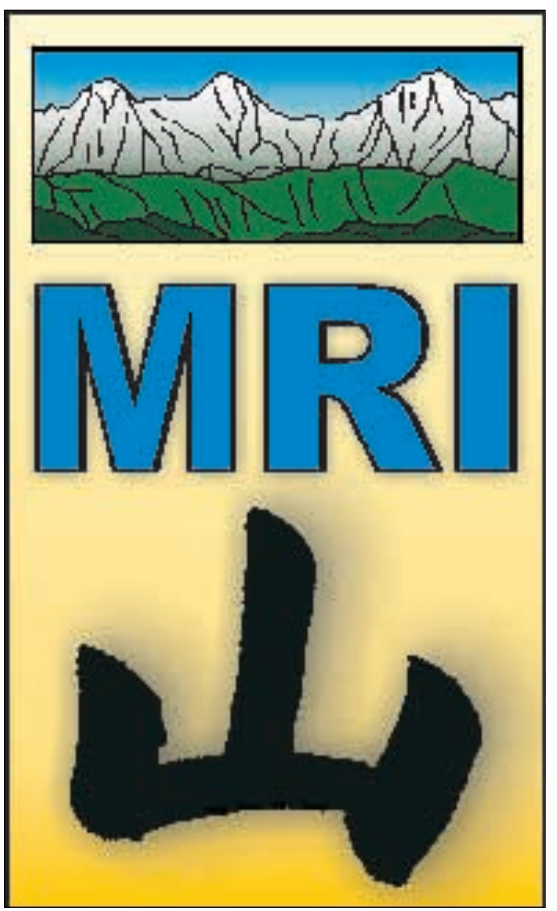

In order to address the consequences of global change in mountain regions, an initiative for collaborative research on global change and mountain regions - the Mountain Research Initiative (MRI) - was developed and officially launched in July, 2001. This initiative formulates and coordinates an integrated, multidisciplinary approach to observing, modeling and investigating global change phenomena and processes in mountain regions, including impacts on ecosystems and socio-economic systems (Fig. 1). The MRI has been formally endorsed by the International Human Dimensions Programme on Global Environmental Change $(\mathrm{IH}-$ DP), Global Terrestrial Observing System (GTOS) and the four core projects of the International Geosphere-Biosphere Programme (IGBP): PAGES, Global Change and Terrestrial Ecosystems (GCTE), Biospheric Aspects of the Hydrological Cycle (BAHC) and Land-Use and Land-Cover Change (LUCC).

Collaboration with PAGES activities will form an integral part of the overall structure of the MRI program. Understanding the presentday and future status of mountain systems such as glaciers, terrestrial ecosystems, and permafrost requires a detailed knowledge of the natural environmental variability that prevailed prior to anthropogenic forcing. Studies of past environmental change in mountains are extremely important and valuable in this context due to the inherent climatic sensitivity of mountain ecosystems. Further, processes such as climatic forcing and ecosystem dynamics operate and interact on a wide range of time scales, from individual extreme events to century- and millennial-scale variability to glacial cycles. Documenting process dynamics on all of these time scales will require a diversity of methods and archives.

From a scientific point of view, the altitudinal gradients in mountain regions provide unique opportunities to detect and analyze global change processes and phenomena because meteorological, hydrological, cryospheric and ecological conditions change markedly over relatively short distances. Accordingly, biodiversity tends to be high, and characteristic sequences of ecosystems and cryospheric systems are found along mountain slopes. The boundaries between these systems (e.g. ecotones, snowline, glacier boundaries) may experience rapid shifts due to environmental change. The higher parts of many mountain ranges are not affected by direct human activities and may serve as locations where the environmental impacts of climate change alone, including changes in atmospheric chemistry, can be studied. Mountain regions are distributed all over the globe,

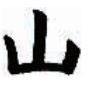
This is the Chinese character for mountain from the Equator almost to the poles and from oceanic to highly continental climates. This global distribution provides opportunities to carry out comparative regional studies from widely separated parts of the globe and to analyze the regional differentiation of environmental change processes.

The ultimate objectives of the MRI are:

1) To develop a strategy for detecting signals of global environmental change in mountain environments. The emphasis of the first objective is on monitoring change in the biophysical environment, and on understanding the interacting ecological and hydrological processes in mountain regions, both with and without local human interference, along altitudinal and other gradients (e.g. land use). Such work recognizes the unique value of many mountain ecosystems that have been and remain relatively uninfluenced by direct human activities, especially in protected areas such as parks and biosphere reserves. An important aim of this objective is to develop a network of observation sites in mountains to serve as an 'early warning' system for detecting global change impacts.

2) To define the consequences of global environmental change for mountain regions as well as lowland systems dependent on mountain resources (highland-lowland interactions). The emphasis of this objective is to increase our understanding of the consequences of global environmental change for people and ecosystems. Credible impact assessments form the baseline for informing policymakers on issues of global environmental changes at local to global levels. In addition, information from impact assessments has direct application to policies and strategies 
for resource management that are implemented at local and regional scales.

3) To facilitate sustainable land, water, and resource management for mountain regions. The emphasis of the third objective, initiating sustainable development strategies, is to define a set of potential human responses to global environmental change that can be implemented at local and regional scales. Scientific results developed under this objective will assist policymakers by indicating the extent of degradation of key mountain resources, and by evaluating interactions between alternative resource management strategies and trajectories of change generated by global factors.

To achieve the above objectives, the research under the MRI is structured around four activities, each of which is divided into a small number of specific tasks.

\section{Activity 1: \\ Monitoring and Analysis}

This element of the Initiative will focus on mountain-specific indicators of environmental change, which are sensitive to changes in climate, atmospheric chemistry, radiation, and land use/land cover. A set of four mountain-specific indicator groups is considered:

1.1) Cryospheric indicators related to snow conditions, glaciers, permafrost and solifluction processes;

1.2) Terrestrial ecosystems, particularly mountain plant communities and soils;

1.3) Freshwater ecosystems, in particular high mountain streams and lakes; and

1.4) Watershed hydrology, i.e. water balance components of high mountain watersheds/headwater basins.

Contemporary monitoring will be arranged within the context of reconstructions of longer-term past trends and variability. Therefore, it is crucial that new monitoring sites in different mountain regions are located at or near sites where historical and paleorecords can be made available, so that the results from

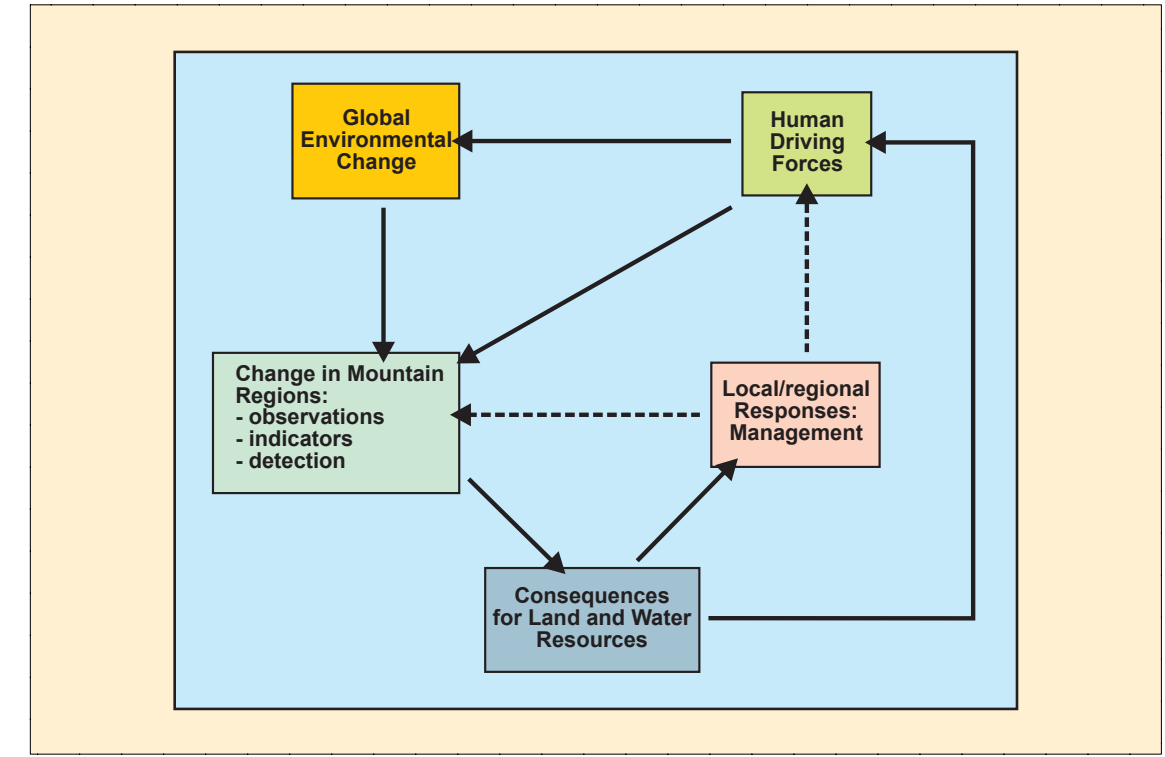

Fig. 1: Conceptual framework for the integrated study of global environmental change in mountains, emphasising feedbacks that occur both within a given mountain region (inner loops) as well as at the global scale (outer loop).

recent observations and research can be related directly to past variability. Paleorecords in general will be used to reconstruct past dynamics of climatic, hydrological and ecological conditions. Most important in this context are:

a) paleoecological reconstructions based on pollen, diatom, fossil pigment and macrofossil (including arthropod) profiles from lakes and mires;

b) lake studies, via reconstructions of flood related sedimentation layers, shore-line fluctuations and both temperature and salinitylinked biotic variations in the sediment record;

c) analysis of cores taken from ice, snow and even permafrost, in particular those providing information on fluctuations in the amount and sources (e.g. using stable isotopes) of past precipitation in mountain regions;

d) dating of geomorphic features associated with past climate change (e.g. moraines) and

e) tree ring analyses in regions where either moisture availability or temperature was the dominant stress on tree growth.

\section{Activity 2: Integrated modeling}

To achieve the overall goals of the initiative, it is necessary to develop a framework that permits the analysis and prediction of hydrological and ecological characteristics and their linkages with land use and climate. Accordingly, this activity is organized around the following:

2.1) Development of coupled ecological, hydrological and land use models for the simulation of land cover and land surface processes in complex mountain landscapes;

2.2) Development of high resolution regional scale atmospheric models for mountain regions;

2.3) Integrated analysis of environmental change in mountain regions by means of fully coupled land-atmosphere models; and

2.4) Regional scale mountain land process experiments complementing modeling efforts.

The modeling activities proposed here require close coordination with the long-term monitoring and process studies conducted under Activities 1 and 3, including reconstructions of past environmental dynamics from paleorecords. The potential for the development of fully coupled land-atmosphere models for mountain regions is particularly exciting. These models could prove very useful for predicting the effects of land use/land cover and climate changes on spatial scales appropriate for the investigation of global change in mountain regions. The predictive utility of these models, however, will only be robust if they are validated with paleoenvironmental records from sensitive 


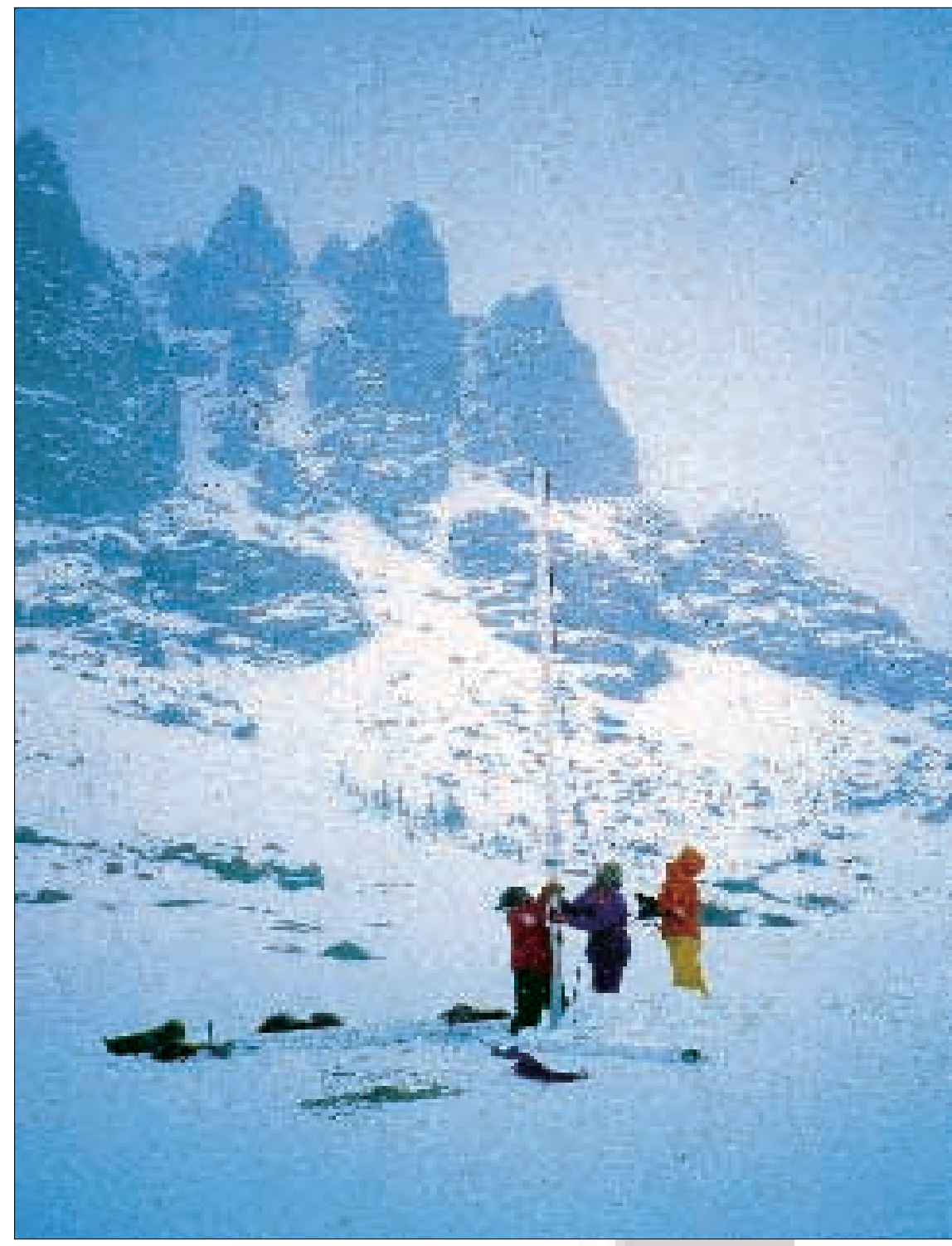

Fig. 2: A lightweight percussion coring system designed for remote access being used to recover a continuous 14,000-year lake sediment record from Sky Pond (3320 $\mathrm{m}$ asl) in the Colorado Front Range. The Sky Pond record provides the first clear indication that changes in late-glacial and early Holocene vegetation near timberline in the Rocky Mountains were in phase with the Younger Dryas climatic oscillation in the North Atlantic region. Additional paleo records from climatically sensitive high elevation sites are required from mountain regions around the world to complete the picture of regional paleoenvironmental changes.

terrestrial sites. Mountain regions provide excellent opportunities for the acquisition of such information.

\section{Activity 3: Process Studies}

Ecological and hydrological field studies and experiments along altitudinal gradients and at sensitive sites can provide invaluable data on potential responses of mountain ecosystems to anthropogenically induced environmental change. Research themes to be addressed within this Activity include:

3.1) Development of indicators of mountain ecosystem response to environmental forcing factors to fa-

\section{Activity 4:}

\section{Resources Management}

The overall objective of this Initiative is to evaluate and enhance sustainable land, water, and resource management strategies for mountain regions. Three priority areas are suggested for assessment:

4.1) Changes in forest resources, with potential implications for agriculture, rates of erosion and magnitude of floods, and biodiversity;

4.2) Intensification and/or extensification of agriculture (including grazing), with potential implications for food security, rates of erosion and magnitude of floods, and biodiversity; and

4.3) Changes in water resources due to factors such as changing agricultural practices, increasing temporary or permanent population, and increasing energy generation, with implications for downstream water supply, energy availability, flooding, and sediment transfer.

From its inception, the MRI has acknowledged that PAGES activities must play a central role in the overall objectives of the Initiative. Researchers involved with reconstructing past environmental change have long recognized that mountain regions are often ideal locations for the study of past global change processes (Fig. 2). The other side of the coin is that their sensitivity renders mountain regions particularly vulnerable to the many anticipated changes of the $21^{\text {st }}$ Century. Understanding this vulnerability is extremely important for humankind considering the large number of people who may be directly and indirectly impacted by changes in mountain regions. Consequently, the development of credible scenarios for the management of mountain environments is an urgent priority. The MRI will contribute not only to the scientific understanding of ongoing processes of change, but will ultimately provide foundations for policies that act to preserve the ability of mountain regions to provide the goods and services on which humanity has come to depend. ies can be used to tie recent experimental and monitoring activities to sediment-based research. 